\title{
Interview
}

\section{Afscheidsinterview met mr. W.A.M. van Schendel, oud-voorzitter van de strafkamer van de Hoge Raad}

\author{
Mr. D.J. (Douwe) Herbrink*
}

\section{NTS 2020/74}

Per 1 september 2020 is mr. W.A.M. (Willem) van Schendel, vicepresident van de Hoge Raad en voorzitter van de strafkamer, met pensioen gegaan. Hij is opgevolgd door mr. V. (Vincent) van den Brink, die reeds sinds 1 juni 2020 de taken als voorzitter van de strafkamer heeft overgenomen. Van Schendel werd in november 2001 benoemd tot raadsheer in de Hoge Raad der Nederlanden en maakte tot 1 januari 2005 deel uit van de strafkamer. Vervolgens nam hij plaats in de civiele kamer. $\mathrm{Na}$ zeven jaren civiele zaken te hebben gedaan is Van Schendel in 2012 als vicepresident de strafkamer weer komen versterken. Van Schendel was eerder rechter in de rechtbank Rotterdam en raadsheer in en vicepresident van het hof Amsterdam.

$\mathrm{Nu}$ Van Schendel de persoon was die eerder dit jaar het allereerste exemplaar van het Nederlands Tijdschrift voor Strafrecht in ontvangst nam, wil NTS zijn afscheid van de Hoge Raad onder geen beding ongemerkt voorbij laten gaan. Daarom trof ik Van Schendel op 13 augustus 2020 , midden in het zomerreces, in een wegens thuiswerkmaatregelen extra verlaten Hoge Raad om hem enkele vragen te stellen over onderwerpen waar de redactie van NTS hem graag over wil horen vertellen.

* Mr. D.J. Herbrink is wetenschappelijk medewerker bij de Hoge Raad en redactiesecretaris van dit tijdschrift.
Omdat Van Schendel in de eerste plaats civilist is en, gelet op zijn proefschrift (W.A.M. van Schendel, Vertegenmoordiging in privaatrecht en bestuursrecht. Een internrechtsvergelijkend onderzoek naar de vertroumensbescherming in geval van onbevoegde vertegenmoordiging (diss. Leiden) Deventer: Kluwer 1982) misschien zelfs generalist kan worden genoemd, ontkomen we niet aan vragen die niet uitsluitend over het strafrecht gaan. De volgende onderwerpen passeren achtereenvolgens de revue: civiel recht in het strafrecht, de vordering benadeelde partij, rechtsbescherming, de 'geen belang'-redenering, ambtshalve cassatie, de 'billijke rechter', de zichtbaarheid van de Hoge Raad in de trias politica en de levenslange gevangenisstraf. Ik val meteen met de deur in huis.

Zijn civiele (bemijsrechtelijke) benaderingswijzen door de jaren heen een grotere rol gaan spelen bij strafprocesrechtelijke vraagstukken? Bijvoorbeeld in situaties waarin een wat actievere opstelling van de verdachte wordt verwacht, zoals in situaties maarin de verdachte bij een bepaalde bewijspositie wat heeft uit te leggen en dat aan het uitblijven daarvan conclusies mogen morden verbonden.

"Het burgerlijk recht heeft natuurlijk altijd een rol gespeeld in het strafrecht. Al was het maar vanwege de vordering van de benadeelde partij en materiële vragen die op burgerlijk rechterlijk terrein liggen of daarin meer zijn uitgekristalliseerd, zoals bijvoorbeeld causaliteit. Ik denk dat een meer rechtsvorderlijke benadering begonnen is bij de ontneming van wederrechtelijk verkregen voordeel. In het kader van die vordering had je een uitgebreid rapport waarin stond waarom een bepaald bedrag wederrechtelijk verkregen was. De ver- 
dediging kon dan niet volstaan met op te merken: 'Nee dat klopt niet, bewijs het maar.' Wat volgt is een soort van 'civielerig procesje' binnen het strafrecht over die ontnemingsvordering met schriftelijke reacties in de vorm van een conclusie van antwoord, repliek en dupliek.

Het aardige van civiel recht vind ik zelf dat je met een blanco scherm begint. Het strafrecht is veel meer gestructureerd. De vrijheid die je hebt om een verhaal te vertellen en om argumenten te wegen, is typisch civiel. Maar voor beide rechtstelsels geldt als leidraad: hoe maak je een nette afweging van alle betrokken belangen en aspecten die bij de beslissing een rol spelen.

Een groot verschil tussen een civiele procedure en een strafrechtelijke is dat - grofweg gezegd - de civiele procedure twee partijen kent. Het is dan makkelijker om met betrekking tot de bewijspositie en bewijslastverdeling te kijken naar welke aspecten bij die twee partijen een rol spelen. Wie van de twee heeft de bewijslast? In het strafrecht is dat anders. Het Openbaar Ministerie draagt de bewijslast in verband met het vervolgingsmonopolie. Desalniettemin kan het voorkomen dat binnen die bewijspositie feiten en omstandigheden worden aangevoerd die het noodzakelijk maken dat er een weerwoord komt. Een dergelijke redeneerwijze is in het civiele recht een vanzelfsprekendheid: ik beweer wat, jij beweert wat en het ene verhaal ontkracht het andere niet of is niet sterk genoeg. Hoewel ik denk dat dat in het strafrecht heel vroeger niet een gebruikelijke manier van wegen was, is het wel reëel op het moment dat er allerlei voor de verdachte belastende omstandigheden liggen waartegen de verdachte dan meer moet zeggen dan 'nee', wil hij of zij die omstandigheden redelijkerwijs ontkrachten. Of van dergelijke benaderingswijzen in het strafrecht tegenwoordig meer gebruik wordt gemaakt dan vroeger weet ik niet, maar het zou me niet verbazen.

In het strafrecht wordt tegenwoordig wel veel meer gebruik gemaakt van motiveringsverplichtingen. Dat is een typisch Hoge Raad-instrument om greep te krijgen op zaken, om vergelijkbare zaken te kunnen vinden en om meer rechtseenheid te kunnen creëren. Dan kan de Hoge Raad de motivering van de feitenrechter op begrijpelijkheid toetsen en daarmee inzicht geven welke omstandigheden voor de uitkomst wel of niet toereikend of bepalend zijn. Dat is ook wat je ziet in het boek van Vincent Peeters (V.J.W. Peeters, Gezichtspuntencatalogus in de strafrechtspraak Een analyse en maardering in het licht van de positie van petgever, feitenrechter en procespartijen, Weert: Celsus juridische uitgeverij, 2020 red.). Het is interessant om te zien dat het hanteren van de methode om in het civiele recht als vanzelfsprekend diverse factoren te benoemen die voor de beslissing van belang zijn, bijvoorbeeld de 'Kelderluik-factoren', in het strafrecht minder vanzelfsprekend was. Het meegeven van aandachtspunten, mogelijke factoren en gezichtspunten die de rechter kan gebruiken bij het nemen van een beslissing, is van oorsprong vooral een civiele manier van redeneren. Omdat elke zaak van een bepaald type ook in het civiele recht toch in feite anders is, is men ermee vertrouwd om op deze wijze enig houvast te vinden. Zo'n gezichtspuntenbenadering past, met inachtneming van de eigen aard, ook in het strafrecht. De strafkamer van de Hoge Raad doet dit dus ook.

Neem het schoolvoorbeeld belaging. In HR 29 juni 2004, ECLI:NL:HR:2004:AO5710 maakte de strafkamer van de Hoge Raad zo'n beetje voor de eerste keer uitdrukkelijk van dergelijke gezichtspunten gebruik. Belaging is een vaag begrip. Wanneer is daar sprake van? Dan probeer je als Hoge Raad factoren te benoemen die de feitenrechter houvast geven bij de beslissing of wel of niet daarvan sprake is. Dat hangt af van de aard, de duur en de frequentie van de gedragingen van de verdachte. Dat geeft enig houvast. Het op een dergelijke manier weergeven van factoren die van belang zijn, geeft de feitenrechter ook de mogelijkheid om flexibel te zijn. Misschien acht hij een andere factor eigenlijk ook wel van belang. Het recht is een levend instrument. Toen ik begon in de jaren 80 van de vorige eeuw zou een beroep op overmacht kunnen worden afgedaan met: 'Het is niet aannemelijk geworden.' Dat gebeurt niet meer. De noodzaak om te motiveren zorgt ook voor de noodzaak om handvatten te hebben om die motivering te toetsen. Het benoemen van factoren kan daarbij zowel de partijen als de Hoge Raad helpen. Ik denk dat dat wel een civiele kant heeft.

Verder is het strafrecht natuurlijk ook een eigen rechtsgebied. Het laten leveren van tegenbewijs door de verdachte is niet aan de orde, maar er mag best van een verdachte worden gevergd dat hij of zij een verklaring geeft voor iets wat om een verklaring schreeuwt, op straffe van ongeloofwaardigheid, bijvoorbeeld als bepaalde relevante factoren wel heel erg in de richting van de verdachte wijzen.”

In hoeverre heeft de Salduz-problematiek en het gegeven dat steeds meer verdachten zich op hun zmijgrecht beroepen invloed gehad op het frequenter toepassen van de redeneertrant dat van de verdachte een verklaring mag morden verpacht?

"Ik weet niet of er veel meer wordt gezwegen in het strafproces en, als dat zo is, of Salduz daartoe heeft geleid. Misschien dat de verdachte bij het eerste politieverhoor wat vaker zwijgt op advies van zijn advocaat, maar of dat dan uiteindelijk op de zitting in hoger beroep nog steeds het geval is, weet ik niet. Ook gevoelsmatig heb ik niet het idee dat zwijgen vaker voorkomt en dat daar door rechters een bepaalde conclusie aan wordt verbonden. De redeneertrant is, bijvoorbeeld in het geval van medeplegen, eigenlijk een hele praktische. Er is een inbraak gepleegd en even later worden er drie personen aangetroffen in een auto met de buit. Je mag dat een bewijsvermoeden noemen, maar het is ook een aanwijzing die maakt dat elk van de drie iets heeft uit te leggen. Je hebt in het strafrecht meer belangen die tegen elkaar moeten worden afgewogen dan in het civiele recht. Naast de verdachte vergen ook slachtoffers en de 
maatschappij dat waarheidsvinding plaatsheeft. Daarnaast heb je de belangen van de Staat in de vorm van de vervolging door de officier van justitie. Het is een gecompliceerder proces. Als iets, zoals in het genoemde voorbeeld, eruitziet als betrokkenheid bij die inbraak dan kun je, bij het uitblijven van een redelijke verklaring, vanuit maatschappelijk oogpunt toch niet negeren dat die jongens daar met zijn drieën een half uur na die inbraak met de buit in die auto zitten? Dan kun je aan die omstandigheid niet zonder nadere overwegingen voorbijgaan."

In HR 15 oktober 2019, ECLI:NL:HR:2019:1465 vernietigde de Hoge Raad het oordeel van het hof dat drie slachtoffers van een inbraak recht hadden op smartengeld. Hoemel het hof marginaal motiveert, loopt de Hoge Raad met deze beslissing niet uit de pas met een tendens in de feitenrechtspraak om niet te moeilijk te doen bij het toekennen van immateriële schade?

"Ik weet niet of de Hoge Raad uit de pas loopt. Er is een maatschappelijke behoefte om smartengeld toe te kennen in dergelijke situaties, maar we zijn wat betreft het toekennen van immateriële schade wel gebonden aan de grenzen van het civiele recht. Ik denk dat de strafkamer van de Hoge Raad met deze zaak aan de ene kant wilde voorkomen dat het feit dat de diefstal van een sieraad dat iemand dierbaar is en emotionele waarde heeft, direct leidt tot aanspraak op immateriële schadevergoeding. Die grens heeft de Hoge Raad ook met zoveel woorden getrokken. Aan de andere kant wordt ook de ruimte gegeven dat een inbraak onder omstandigheden wel tot vergoeding van smartengeld kan leiden. De grens ligt echter wel bij wat het civiele recht toelaat.

Ik vind het een interessant verschijnsel dat de discussie over bijvoorbeeld immateriële schadevergoeding zich inmiddels voor een groot deel afspeelt in het strafrecht. Veel van dit soort vorderingen tot schadevergoeding komen helemaal niet meer voor de civiele rechter. Ik zat in de civiele kamer tijdens de behandeling van een shockschade-zaak (HR 9 oktober 2009, ECLI:NL:HR: 2009:BI8583). Shockschade is een niet eenvoudig toe te wijzen soort schade. Daar hebben we toen strenge eisen aan gesteld. Daarna kwam ik in de strafkamer en hebben wij in eerste instantie gezegd dat shockschade zo'n ingewikkeld vraagstuk is dat een strafrechter dat niet moet behandelen. Dat heeft aan de ene kant te maken met de zorgvuldigheid van de civiele procedure en aan de andere kant met het feit dat het onderwerp nog in ontwikkeling was. Dat is tegenwoordig niet meer zo. Als je het goed motiveert volgens de lijnen van het civiele recht, kan het ook in het strafrecht worden behandeld. Zulke rechtsvragen op het terrein van schadevergoeding vergen afstemming met de civiele kamer. De omvang van de verplichting tot vergoeding van immateriële schade, bijvoorbeeld ook de betekenis daarbij van (voorwaardelijk) opzettelijk toegebrachte schade is nog niet uitgekristalliseerd.
In het overzichtsarrest over de vordering benadeelde partij (HR 28 mei 2019, ECLI:NL:HR:2019:793) hebben we de grenzen voor iedereen nog eens op een rijtje gezet. Daaruit is ook af te leiden welke ruimte er is. Als wij het hebben over de aard en de ernst van de normschending, dan zit daar ruimte in. Daarbij speelt ook mee wat er in de maatschappij leeft. Toen ik 80 jaar geleden als rechter begon (geintje - red), zou er geen denken aan zijn geweest dat shockschade voor vergoeding in aanmerking zou komen of dat immateriële schade bij een woninginbraak zou worden toegekend. Toch is dat in de loop der jaren tot ontwikkeling gekomen. Zowel in de wetgeving, maar ook in de maatschappelijke discussie daarover die ook te maken heeft met de versterking van de positie van het slachtoffer in het strafrecht. Dat is wel een interessante wisselwerking. Ik denk dat de meeste vragen van immateriële schade of zelfs wel van schadevergoeding zich eerder in het strafrecht gaan ontwikkelen dan in een civiele procedure."

De rechter volgt de mens van de metgever om de vordering van benadeelde partijen zo veel mogelijk in het strafgeding te beoordelen. De tendens is veranderd van 'nee, mant een onevenredige belasting voor het strafgeding, tenzij' naar ' $j a$, al is het maar ten dele, mits'. Het een en ander leidt er mellicht toe dat er vaker een complexe vordering in het strafproces mordt behandeld. Beschikt de strafrechter mel over voldoende civiele expertise?

"Daar heb ik altijd al wel wat van gevonden. Je kunt het aan de ene kant de slachtoffers niet aandoen om een civiele procedure te beginnen. Toen ik begon had je in het strafrecht een beledigde partij vordering die was gefixeerd op 1500,- gulden. Dat is natuurlijk niet de waarde van een voorwerp of van de schade, maar het gaf wel rust, want meer dan 1500,- gulden kon het niet zijn. Dat is niet meer. Dat betekent dat die vorderingen gecompliceerder worden. In een civiele procedure heb je een conclusie van antwoord, repliek, dupliek, comparities, bewijsopdrachten. Dat is in het strafrecht veel lastiger. Daar leent de procedure zich eigenlijk niet voor. De verdachte wordt bijgestaan door een, ik schets even het slechtste scenario, strafrechtelijke advocaat die geen idee heeft van het civiele recht, bijvoorbeeld met betrekking tot verplaatste schade of causaliteit. Het heeft bovendien iets naars om, ook al is dat terecht, als advocaat te zeggen: 'Ik betwist die vordering', terwijl het slachtoffer in de zaal zit, de officier van justitie het eens is met het slachtoffer en de verdachte juist een goede indruk wil maken op de rechter. Dat makt het tot een onevenwichtige procedure voor een gecompliceerde vordering. Dat doet niet helemaal recht aan de positie van het slachtoffer, maar ook niet aan de positie van de verdachte. Ik vind dat we uiteindelijk naar een procedure moeten die de vordering van de benadeelde partij van de eigenlijke strafrechtelijke procedure loskoppelt. Ik voel dus best iets voor een schadevergoedingsrechter of een schadevergoedingskamer. De vordering van de benadeelde partij kan dan hopelijk ook veel eerder dan in het ergste geval pas na een aantal jaren, bijvoorbeeld pas na 
vernietiging in cassatie en terugwijzing, definitief worden.

Daarnaast zou je een forfaitaire regeling kunnen maken. Een vooraf bepaald vast bedrag voor bijvoorbeeld een woninginbraak. Siewert Lindenbergh en anderen hebben onderzoek gedaan naar de beleving van slachtoffers bij het verhalen van schade in strafrechtelijke en civielrechtelijke procedures (J.D.M. van Dongen, M.R. Hebly \& S.D. Lindenbergh, fe hebt geluk als je van een paum mag plukken, ervaringen van slachtoffers van strafbare feiten met het verhalen van hun schade, Den Haag: WODC 2013 - red). Dat onderzoek heeft uitgewezen dat slachtoffers tevreden kunnen zijn met een zeker bedrag. En dan gaat het ze er eigenlijk niet eens om of dat bedrag $€ 283,30$ is, maar meer om de in de toekenning van dat bedrag besloten liggende erkenning van het leed dat hun is aangedaan. Schadevergoeding bij letselschade bestaat ook uit vergoeding van smartengeld. Daarvoor heb je in het civiele recht een systeem van min of meer forfaitaire bedragen. Dat zou je in het strafrecht eigenlijk ook in kleinere standaardzaken moeten hebben. Dan ben je van veel onzekerheid af.

Die forfaitaire regeling zou wellicht, zo mijmer ik, ook zonder wetswijziging tot stand kunnen komen. Over alimentatie hebben civiele rechters afspraken gemaakt en over ontslagvergoedingen maakten rechters vroeger ook afspraken. Ik denk dat je op die wijze nu al binnen het strafrechtelijk systeem de vorderingen tot vergoeding van immateriële schade kunt behandelen. Afgesproken wordt dat je voor een gewone mishandeling een $\mathrm{X}$ bedrag aan smartengeld krijgt. Zo weet ook de verdachte in een vroeg stadium waar hij aan toe is, uiteraard als het feit vaststaat. Ik zou me kunnen voorstellen dat dit in vorm van strafrechtrichtlijnen kan worden gegoten. Een soort LOVS-richtlijnen in de schadevergoedingssfeer, even afgezien van de bindende kracht ervan. Ik kan mij voorstellen dat een forfaitaire regeling kan helpen bij een versnelling van de procedure en tegelijk ook een zekere bevrediging voor slachtoffers geeft.

Het blijft lastig om een balans te vinden tussen de versterkte rol van het slachtoffer in het strafproces, zijn vordering, zijn spreekrecht en het tegelijkertijd overeind houden van de rol voor de verdachte en de verdediging. Dit is niet helemaal op te lossen. Het nieuwe wetboek geeft in ieder geval nog niet een volkomen eenduidige nieuwe doordenking van de positie van het slachtoffer en de benadeelde partij. Ik vind overigens ook dat het redelijk is dat de benadeelde partij een eigen cassatieingang krijgt. Die hebben we HR 4 juli 2017, ECLI:NL:HR:2017:1277 alleen niet zelf kunnen creëren omdat de wet dat uitsloot. Maar dat gaat veranderen.”

In haar proefschrift (A.E.M. Röttgering, Cassatie in strafzaken. Een rechtsbeschermend perspectief (diss. Tilburg), Den Haag: Sdu Uitgevers 2013) constateerde Röttgering onder meer dat-kort gezegd - binnen het strafrecht grofmeg twee richtingen zijn te onderscheiden, de rechtsbeschermende en de instrumentele. De Hoge Raad is volgens haar vooral instrumenteel: het strafrecht moet "merken". Kunt u zich vinden in die typering?

"Het strafrecht moet zeker werken. Het moet de daad zien te vinden, de dader zien te vinden en het moet bestraffen. Ik geloof eigenlijk niet dat er een tegenstelling is tussen instrumentalisme en rechtsbescherming, niet in die mate in ieder geval. Als het strafrecht werkt, werkt het pas goed als het de verdachte het volle pond geeft, het slachtoffer het juiste pond geeft en de maatschappij het juiste pond geeft. Zo beschouwd zie ik die tegenstelling eigenlijk helemaal niet. Als wij zeggen dat het oordeel dat sprake is van voorbedachte raad goed gemotiveerd moet worden, dan heeft dat ook een rechtsbeschermend effect. Zo wordt niet te snel de hoogste straf opgelegd. Als wij over roekeloosheid zeggen dat dit de hoogste vorm van schuld is en hiervan niet reeds sprake is als iemand te hard rijdt en gedronken heeft, dan heeft dat een rechtsbeschermend effect voor een heleboel andere zaken. Dan is het een werkend systeem en heeft het op een zaaksoverstijgend niveau ook een rechtsbeschermende functie. Ik weet dat vaker wordt gezegd dat de Hoge Raad, door de focus op rechtsontwikkeling, de rechtsbescherming minder hoog in het vaandel heeft staan. Ik waag dat eerlijk gezegd te betwijfelen. Het is juist onze taak om, in concrete zaken, maar ook door middel van overzichtsarresten, meer algemene regels te geven en zoveel mogelijk handvatten te bieden aan de procespartijen. Dat biedt tegelijkertijd die beschermende functie. Omdat men weet welke factoren een rol kunnen spelen, weet men ook van tevoren waar men aan toe is. Als je weet wat de Hoge Raad van belang vindt, dan weet je als verdediging ook wat de elementen zijn die benadrukt moeten worden bij het bepleiten van vrijspraak. De rechtsbeschermende en de instrumentele benaderingen vallen samen eigenlijk."

In HR 29 januari 2019, ECLI:NL:HR:2019:79 oordeelde de Hoge Raad dat de verdachte geen in rechte te respecteren belang heeft bij zijn klacht, ook al blijkt wit het laatste proces-verbaal van de terechtzitting in hoger beroep niet dat hem het recht is gelaten het laatst te spreken. De casus is als volgt:

(i) ter terechtzitting van 23 mei 2016 is de verdachte het recht gelaten om het laatst te spreken en is het onderzoek onderbroken tot de dag erna, maar formele sluiting zou plaatsvinden, (ii) ter terechtzitting van 24 mei 2016 is het onderzoek hervat in de stand maarin het zich bevond, (iii) de raadsman heeft toen een beroep gedaan op de nietigheid van dagvaarding met betrekking tot feit 3 en de AG heeft gerekmireerd tot vermerping van dat vermeer, maarna het onderzoek is gesloten, (iv) het hof heeft de dagvaarding met betrekking tot feit 3 bij eindarrest nietig verklaard en (v) het cassatieberoep is niet gericht tegen die (gedeeltelijke) nietigverklaring van dagvaarding. 
Gaat het niet te ver om een mezenlijk recht als het recht op het laatste poord in het strafprocesrecht te relativeren? Zitten er grenzen aan die 'geen belang'-redeneringen?

"Dat is geen rechtsbescherming zegt men dan. Maar als je dat belang niet hebt, wat valt er dan nog te beschermen? Natuurlijk is er een grens, bijvoorbeeld daar waar de beginselen van een goede procesorde in wezenlijke mate zijn geschonden. Maar als je geen belang hebt bij het middel, of bij vernietiging in cassatie, dan valt er eigenlijk niets te beschermen. Ik maak de vergelijking met vormverzuimen. In de jaren ' 80 -'90 van de vorige eeuw was er verontwaardiging in de maatschappij dat een vormverzuim, ook een miniem verzuim, kon leiden tot vrijspraak of tot niet-ontvankelijkheid, terwijl het feit wel gewoon was gepleegd. Er was sprake van maatschappelijke druk om te zeggen dat het niet redelijk is om iemand vrijuit te laten gaan die het wel gedaan heeft. Bij ons is dit begonnen met een zaak (HR 25 juni 2002, ECLI:NL:HR:2002:AD9204) die nog heeft geleid tot het proefschrift van Reindert Kuiper (R. Kuiper, Vormverzuimen: Furidische consequenties van vormverzuimen in strafzaken (diss. Nijmegen), Deventer: Kluwer 2014 red). Bij fouillering moeten er ernstige bezwaren zijn. Die waren er in die zaak niet, maar de politie fouilleerde toch en vond een doorgeladen pistool. De verdachte werd vervolgd voor het hebben van dat doorgeladen pistool. Moet de rechter dan zeggen: 'U wordt vrijgesproken. $\mathrm{U}$ had wel een doorgeladen pistool, maar het is niet op de juiste manier aangetroffen.' Daar is voor de eerste keer die belangenafweging uitdrukkelijk aanvaard. Is het verantwoord om tegen een slachtoffer, de maatschappij, de bezitter van dat wapen te zeggen dat deze vormfout noodzakelijkerwijs altijd tot vrijspraak of niet-ontvankelijkheid leidt? Dat heeft zich ontwikkeld tot wat artikel 359a $\mathrm{Sv}$ is geworden en de jurisprudentie daarover. $\mathrm{Ik}$ vind dat nog steeds een verstandige benadering om een afweging te maken tussen al de daarbij betrokken belangen. Hoe die moet uitvallen is uiteraard een ander chapiter.

Ten aanzien van de zaak van 29 januari 2019 merk ik het volgende op. Wij zijn in beginsel heel streng. Staat er niet in het proces-verbaal dat je het laatste woord hebt gehad, dan sneuvelt het arrest daarop. Zo hadden we eens een zware, grote zaak uit Amsterdam met veel zittingen en in het laatste proces-verbaal ontbrak toen het zinnetje dat de verdachte het laatste woord heeft gehad. Daar hebben we ook toen streng vernietigd, ook al was het misschien een vergissing. In de zaak waar jij nu aan refereert, achtte de Hoge Raad in de bijzondere, opgesomde omstandigheden van het geval dat het recht op laatste woord niet daadwerkelijk was geschonden. Dit betreft dus een hele specifieke zaak en benadrukt de Hoge Raad dat het een beslissing is 'in dit geval'. Er zit natuurlijk wel een grens aan geen belang redeneringen. Je moet er wel met een zekere prudentie mee omgaan."

In HR 9 oktober 2012, ECLI:NL:HR:2012:BX5513 stelt de Hoge Raad vast dat tegen de bemezenverklaring van het niet voldoen aan een bevel krachtens enig mettelijk voor- schrift geen middel is aangevoerd en dat er geen grond is voor ambtshalve cassatie. De CAG houdt echter in dat er geen sprake mas van een vordering krachtens mettelijk voorschrift. Deze zaak mas duidelijk niet gezond, had de Hoge Raad hier niet moeten ingrijpen?

"Dat is ons standpunt over ambtshalve cassatie. De raadsman van de verdachte zou erover hebben kunnen klagen, maar hij doet het niet. Dat is het middelenstelsel dat we hebben in cassatie. Interpretatie van het middel kan natuurlijk altijd, maar als er geen middel is, dan kunnen we niks. Voordat ik bij de Hoge Raad kwam, bekeek de strafkamer de zaken ambtshalve. Er was geen middelenstelsel. Als gevolg van het middelenstelsel ontstaat de vraag wanneer je toch ingrijpt als het middel er niet over gaat. Dat is natuurlijk een beleidsmatige keuze van ons geweest om de ruimte die we hebben om zaken te behandelen te benutten door alleen dat te doen wat door de verdediging op ons bordje wordt gelegd ligt. Dat doet geen afbreuk aan de rechtsbeschermende taak van de Hoge Raad. Het is de verantwoordelijkheid van de verdediging om te klagen over een uitspraak in de vorm van cassatiemiddelen. Dat geldt dus ook in de zaak die je aanhaalt."

In 2017 schreef $u$ in Trema over de billijke rechter (W.A.M. van Schendel, De billijke rechter, Trema 2017, afl. 3, p. 99-104). U haalde daarbij mat billijke (civiele) uitspraken aan van de Hoge Raad. Zijn er ook beslissingen van de strafkamer die u daaraan zou millen toevoegen? Ziet $u$ zichzelf als billijke rechter?

"Dat artikel was een bijdrage aan een symposium van Ybo Buruma waarin hij het had over de billijke rechter als een van de prototypen van rechters. Hij bedoelde daarmee - min of meer - een rechter die een soort list verzint om een goede oplossing te bereiken. In het artikel zeg ik dat dit wel aardig klinkt - ik zou het zelf ook leuk vinden om dat te doen -, maar in wezen is het zo dat iedere keer als de rechter probeert om een evenwichtige of rechtvaardige beslissing te geven, hij dan die billijke rechter is. Dus niet in de zin van: 'Ik verzin een truc om iets te bereiken wat eigenlijk niet kan.' Wat de Hoge Raad altijd doet is het inbedden van een beslissing in een systeem of het zodanig interpreteren van de zaak dat het bij wijze van spreken niet opvalt dat wij bezig zijn om die goede uitkomst te bereiken. Dit is makkelijker te illustreren aan de hand van civiele uitspraken. Dan kun je zeggen dat het redelijk is dat twee mensen de helft betalen en dan schrijf je dat zo op. Het is in het strafrecht veel lastiger om te demonstreren dat je een goede of billijke uitkomst bereikt. Een evenwichtige en behoorlijk gemotiveerde beslissing - dat schaar ik dan even onder billijk - is de uitkomst van een gewetensvolle afweging.

Op het moment dat de Hoge Raad bijvoorbeeld een middel 'opplust' ("het middel strekt kennelijk ten betoge"), is hij net zo goed bezig om een goede uitkomst te bereiken. Dan zorgen we dat we een haakje vinden om 
de beslissing aan op te hangen. Ook dan ben je steeds bezig om te proberen een goede beslissing te nemen. Of dat altijd lukt is natuurlijk de vraag, maar je doet je best. Het is daarom lastig om zo'n beslissing een billijke beslissing te noemen. Ik gaf in het artikel het voorbeeld van de Hangmat zaak (HR 8 oktober 2010, ECLI:NL:HR:2010:BM6095). Hoewel je daarin leest dat het uiteindelijke argument is dat het onredelijk zou zijn om geen vergoeding toe te kennen, zie je ook dat de beslissing wordt ingebed in het systeem en niet dat de Hoge Raad coûte que coûte louter op grondslag van de billijkheid een beslissing geeft.

Ik kan niet zeggen dat ik mijzelf zie als een billijke rechter. Ik kan hoogstens zeggen dat ik mijn best doe om een goede beslissing te nemen. Billijk is hier niet het juiste woord voor. Ik zou het willen formuleren als het nemen van een goede, nette, zo zorgvuldig mogelijk gecomponeerde beslissing die past in het systeem en die recht doet aan de belangen van iedereen die erbij betrokken is. Het nemen van een rechtvaardige en redelijke beslissing die daarnaast pragmatisch is, gaat prima samen. Het is net zo als met dat instrumentalisme en die rechtsbescherming. Natuurlijk verhoudt zich dat tot elkaar. Een zo goed mogelijke beslissing te nemen is ook een beslissing die in de praktijk aanvaardbaar is en die mensen overtuigend vinden, overtuigend kunnen vinden of die je geprobeerd hebt zo te motiveren dat men er in de praktijk verder mee komt."

In zijn voordracht tijdens het Symposium voor de magistraat van morgen van 1 november 2019, 'Tansformations of the legal basis for the functioning of the judiciary in Poland, lessons to be learnt', deelde dr. Grzegorz Borkomski (rechter in Polen en oud-voorzitter van de Poolse Raad voor de rechtspraak) mede dat zijns inziens de rechtelijke macht in Polen ook zelf een aandeel heeft gehad in de veranderingen die de Poolse rechtstaat nu doormaakt, omdat zij onvoldoende zichtbaar is gemeest, onvoldoende haar stem heeft laten horen en te meinig uitleg heeft verschaft over haar rol in de trias politica. Vindt $u$ dat de Nederlandse rechterlijke macht mel in voldoende mate zichtbaar is en haar beslissingen in voldoende mate uitlegt indien nodig? Doet de Hoge Raad dit anders dan tmintig jaar geleden?

"Ik denk dat het belangrijk is dat rechters zich bewust zijn van hun rol in de trias politica. Of het altijd voldoende is weet ik niet, maar we doen ons best om in die trias zichtbaar te zijn. De Hoge Raad doet dat onder meer door een actief extern voorlichtingsbeleid. In zaken waarbij we mondeling uitspraak doen, al dan niet via een livestream, proberen we door middel van een voorleesversie onze beslissing zo duidelijk mogelijk uit te leggen en/of in de andere gevallen via een duidelijk persbericht. Zo probeert de Hoge Raad zichtbaar te zijn en zijn beslissingen in zaken in voldoende mate uit te leggen. Ook onderhoudt de Hoge Raad contacten met de feitenrechters, de advocatuur, het OM en ook met de politiek. Het is goed om je te realiseren dat je op elkaar inwerkt als staatsmachten. De ouderwetse driedeling van afzonderlijke machten bestaat niet (meer). Het is een voortdurende wisselwerking en van die rol moet je je als rechter bewust zijn.

De Hoge Raad is met zichtbaarheid anders bezig dan twintig jaar gelden. We zijn veel nadrukkelijker bezig met onze positie binnen de rechtelijke macht, maar we besteden zoals gezegd ook meer aandacht aan onze verhouding tot de advocatuur en het Openbaar Ministerie. Daarnaast proberen we contacten te onderhouden met het maatschappelijk veld. We verwelkomen graag iedereen op open dagen. Toen ik persraadsheer werd in de Hoge Raad was het maximum dat we in een persbericht durfden te zeggen - ik chargeer -: 'De Hoge Raad heeft gezegd dat het oordeel van het hof niet onbegrijpelijk is.' Dat zullen we nu niet meer zo zeggen. Je probeert in een voorleesversie of in een persbericht in samengevatte vorm duidelijkheid te scheppen en dat beïnloedt vervolgens ook weer het schrijven van het arrest zelf. We zijn veel opener geworden en we zien veel nadrukkelijker het belang dat je moet uitleggen wat je doet. Dat beinvloedt misschien indirect ook weer de rol van Hoge Raad in de trias politica. Er is onlangs een initiatief opgestart van jonge rechters bij de rechtbank Den Haag om het debat over de Trias weer nieuw leven in te blazen. Het doel daarvan is om jonge mensen uit verschillende geledingen die nu of later deel uitmaken van de instituties van de Trias bij elkaar te brengen. Dit is een heel zinvol project dat helaas vanwege corona stil ligt.

Tot slot bij deze vraag wil ik nog zeggen dat een van de dingen die mij toch altijd weer verrast is dat, ondanks dat er soms veel boosheid is in de maatschappij, mensen toch naar de rechter gaan om een beslissing te krijgen, bijvoorbeeld over demonstraties. Men kan ook zeggen: 'We doen het gewoon! Wat kan ons het schelen! We hebben er geen boodschap aan!' Maar men gaat toch naar de rechter om toestemming te vragen of om een verbod te bestrijden. Daar kun je dan wel aan ontlenen dat men in onze maatschappelijke werkelijkheid toch waarde hecht aan de beslissing van de rechter. Uit de Rule of Law Index blijkt ook dat het vertrouwen van het publiek in de rechtspraak in Nederland onverminderd hoog is. Dat vind ik wel bijzonder en stemt ook hoopvol voor de toekomst."

Op melk gebied in het strafrecht hoopt $u$ in de komende jaren in het bijzonder ontwikkeling te zien?

"In de beslissingen van de Hoge Raad over levenslang hebben wij telkens geprobeerd om - onder invloed van Straatsburg, maar dat zijn ook onze eigen normen van de Nederlandse democratische rechtsstaat - te benadrukken dat er perspectief zal moeten zijn op enige herbeoordeling van een opgelegde levenslange straf. De staatssecretaris kwam met het ontwerp van een regeling dat met die normen niet toereikend strookte. De Hoge Raad heeft toen de regelgever een jaar de tijd gegeven om die regeling te verbeteren; een nadere regeling is er gekomen. We zijn nu enige tijd verder. De praktijk leert echter dat zowel positieve gratieadviezen van rechtelijke colleges als zulke 
adviezen van de commissie langgestraften, tot nu toe niet hebben geleid tot enige gratiëring. Ik heb daar bepaald zorgen over. De Hoge Raad heeft niet voor niets met zoveel woorden in een van de arresten in het Passage-proces (HR 23 april 2019, ECLI:NL:HR:2019:600) gezegd dat, indien deze regeling en bijbehorende adviezen de facto nooit tot gratiëring zouden leiden, dat wel eens zou kunnen betekenen dat de oplegging van levenslange gevangenisstraf niet langer toelaatbaar is. Dat zou ook zeer ernstige misdrijven regarderen. Ik hoop in ieder geval dat in de komende jaren aan deze problematiek op een reële manier aandacht wordt gegeven." 